\title{
A CONFIGURAÇÃO DO SIGNIFICADO DE FAMÍLIA PARA HOMOSSEXUAIS: UM ESTUDO FENOMENOLÓGICO
}

\author{
Setting Up The Meaning Of Family For Homosexuals: A Phenomenological Study \\ La Configuración del Significado de la Familia para Homosexuales: Un Estudio Fenomenológico
}

Mariana Alvarenga Rodrigues

Marta Carmo

\begin{abstract}
Resumo: O século XX foi marcado por transformações em diversos campos, incluindo a sexualidade e a constituição familiar. Em decorrência dessas mudanças, tornou-se importante investigar qual o significado de família para homossexuais femininos e masculinos. A pesquisa teve por objetivo principal compreender a configuração do significado de família para homossexuais. Foi realizado um estudo com quatro adultos homossexuais, dois do sexo feminino, e dois, do masculino. Para tanto, realizou-se uma pesquisa qualitativa, pautada na perspectiva fenomenológica e na teoria de campo de Kurt Lewin, fundamento teórico da abordagem gestáltica. Utilizou-se o método fenomenológico de Giorgi (1985), e encontraram-se as seguintes categorias temáticas: processo de autodenominação sexual, configuração do campo após a descoberta da homossexualidade, constituição familiar atual, e, significado de família. Analisou-se que, apesar das mudanças ocorridas na sociedade a família continua mantendo o papel de organizadora. Palavras-chave: Família; Homossexualidade; Configuração; Campo.
\end{abstract}

\begin{abstract}
The twentieth century was marked by changes in various fields, including sexuality and family formation. Due to these changes, it became important to investigate the meaning of family to male and female homosexuals. The research was aimed at understanding the configuration of the meaning of family for homosexuals. A study was conducted with four gay adults, two female and two males. To this end, we carried out a qualitative study, based on the phenomenological perspective and field theory of Kurt Lewin, theoretical foundation of Gestalt approach. We used phenomenological method of Giorgi (1985), and found the following thematic categories: sexual self-designation process, configuration of the field after the discovery of homosexuality, family setting current, and meaning of family. We analyzed that despite the changes in society the family continues to maintain the role of organizing.
\end{abstract}

Keywords: Family; Homosexuality; Configuration; Field.

Resumen: El siglo XX fue marcado por transformaciones en varios campos, incluyendo la sexualidad y la constitución de una familia. En recorrer de todos estos cambios, se puede decir que se torna importante investigar cual es el significado de la familia para personas homosexuales de sexo femenino y los homosexuales de sexo masculino. La pesquisa tiene por objetivo principal comprender la configuración del significado de la familia para homosexuales. Fue realizado un intenso estudio con cuatro adultos homosexuales, dos del sexo femenino y dos del masculino. Para eso, se realizó una pesquisa cualitativa, basada en la perspectiva fenomenológica y en la teoría de campo de Kurt Lewin, fundamento teórico en el abordaje gestáltica. Se utilizó el método fenomenológico de Giorgi (1985), donde se encuentran las siguientes categorías temáticas, que son: el proceso de auto denominación sexual, la configuración del campo después de la descubierta de la homosexualidad, la constitución familiar actual y el significado de la familia. Se visó que a pesar de los cambios ocurridos en la sociedad, la familia continúa manteniendo el papel importante de ser la organizadora.

Palabras-clave: Familia; Homosexualidad; Configuración; Campo.

\section{Introdução}

Esta pesquisa aborda a configuração do significado de família para homossexuais, alicerçando-se, mormente, na teoria de campo de Kurt Lewin. Buscar-se-á verificar o vínculo mantido pelos homossexuais com as famílias de origem, além de elucidar que pessoas compõem sua família atual e, ainda, se ocorreram modificações em sua família após assumir-se homossexual.

Neste estudo, foi utilizado o método fenomenológico proposto por Giorgi (1985) para a compreensão deste fenômeno. Para tanto, propôs-se a questão que norteou a investigação fenomenológica: "como se configura o significado da família para um homossexual?”.

As respostas a esses questionamentos foram buscadas de forma intensa na literatura, bem como no momento empírico. Desataca-se que após a realização do momento empírico, verificou-se que a teoria de campo de Kurt Lewin daria o suporte adequado para a leitura de como esses casais estavam significando o conceito de família, visto que permite uma leitura dos movimentos intrapessoais, bem como a leitura do contexto no qual os pesquisandos se inserem, além de ser uma teoria de base da Gestalt-terapia. 


\section{A Configuração do Significado de Família para Homossexuais}

Vários autores, de diferentes enfoques, conceituam família. De acordo com Zinker (2001), família é uma unidade social, cultural e econômica, um sistema de indivíduos comprometidos a permanecerem juntos por um extenso período de tempo, mantendo uma continuidade no seu relacionamento. Carter e McGoldrick (1995) afirmam que família "compreende todo o sistema emocional de pelo menos três gerações, e agora frequentemente quatro" (p. 9).

Atualmente, existem múltiplas formas de expressão das relações interpessoais e familiares, dentre elas: famílias nucleares, monoparentais, reconstituídas, homoparentais, com filhos biológicos, com filhos adotivos, pais heterossexuais com filho homossexual, inférteis, uniões informais (Santos, 2004; Borges, 2009). Apesar da diversidade de composições de famílias, em sua maioria delas participam um ou mais adultos que se organizam em diversos arranjos (Zinker, 2001).

Visto que a constituição familiar sofre alterações nos dias atuais, o que se denomina família não tem o mesmo significado que há décadas atrás. Essas mudanças ocorreram no Brasil em virtude da transformação das condições de trabalho, da redefinição dos papéis de gênero, conjugais e parentais, da mudança nos valores, do aumento da estimativa de vida. Também, em razão das desigualdades sociais e étnicas, tornaram-se necessários novos arranjos familiares (Santos, 2004).

Apesar de todas as mudanças que ocorreram na configuração da família, essa instituição continua mantendo o papel de organizadora da sociedade ocidental contemporânea. Desvelar o significado de família significa compreender quais são os requisitos para que a união entre indivíduos possa receber este nome (Uziel, 2002).

No Brasil, em 5 de maio de 2011, o Supremo Tribunal Federal reconheceu a união entre pessoas do mesmo sexo como entidade familiar, conforme se segue:

No mérito, prevaleceu o voto proferido pelo Min. Ayres Britto, relator, que dava interpretação conforme a Constituição ao art. 1.723 do Código Civil para dele excluir qualquer significado que impeça o reconhecimento da união contínua, pública e duradoura entre pessoas do mesmo sexo como entidade familiar, entendida esta como sinônimo perfeito de família. Asseverou que esse reconhecimento deveria ser feito segundo as mesmas regras e com idênticas consequências da união estável heteroafetiva (Brasil, 2011).

Dessa forma, o Brasil garantiu que às uniões estáveis homoafetivas cabem todos os direitos conferidos às uniões estáveis heteroafetivas. Uma questão importante para os homossexuais deve-se ao fato de que, desde a década de 1980, o termo homossexualidade foi retirado do Código Internacional de Doenças (CID), significando que, desde então, a homossexualidade não é considerada patológica (Santos, 2004).

Esses avanços possibilitam que gays e lésbicas assumam para si e publicamente, em escala crescente, sua orientação afetivo-sexual e suas parcerias amorosas. Assim, gera-se uma redefinição dos padrões de conjugalidade e parentalidade, rompem-se os limites convencionais, até então restrita ao âmbito heterocentrista (Mello, 2005). Particularmente, os casais homossexuais enfrentam problemas. As dificuldades surgem em virtude da falta de aceitação da família e da sociedade. Tais dificuldades tem como consequência um elevado risco de o casal desenvolver problemas de fronteiras relacionais um com o outro. Além do mais, ocorre a falta de rituais normativos durante o ciclo de vida, pois não podem se casar, se divorciar etc., o que dificulta o reconhecimento da família em suas transições no ciclo de vida, produzindo uma imagem de eternos adolescentes (Carter \& McGoldrick, 1995).

Atualmente, diversos temas vêm sendo pesquisados no campo da homossexualidade, dentre eles, família e homossexualidade (Borges, 2009; Santos, 2004; Uziel, 2002); investigação dos determinantes do comportamento homossexual humano (Menezes, 2005); construção da identidade homossexual (Anjos, 2002; Taquette, Vilhena, Santos \& Barros, 2005); homossexuais femininas (Cancissu, 2007; Palma \& Levandowski, 2008).

\section{Teoria de Campo de Kurt Lewin}

Nesta pesquisa, a configuração do significado de família para homossexuais será analisada com base na teoria de campo de Kurt Lewin, sendo esta uma teoria integrante da abordagem gestáltica. A teoria de campo foi originalmente criada por Kurt Lewin, uma das mais importantes figuras da psicologia moderna. É definida como um conjunto de conceitos por meio do qual é possível representar a realidade psicológica e, nesse sentido, possibilitar que seja lidada e trabalhada (Ribeiro, 1999).

As principais características da teoria de campo proposta por Lewin são: o comportamento é função do campo que existe no momento em que ocorre o comportamento; a análise começa com a situação como um todo; e a pessoa concreta em uma situação concreta pode ser representada matematicamente (Hall \& Lindzey, 1984).

Lewin (1973) utiliza o termo "espaço vital psicológico" para indicar a totalidade de fatos que determinam o comportamento de um indivíduo em um dado momento, ou seja, uma situação psicológica, que pode ser apresentada como a junção de pessoa e ambiente $(\mathrm{EV}=\mathrm{P}+\mathrm{A})$. $\mathrm{O}$ autor esclarece que o ambiente não contém apenas os aspectos físicos, ele abrange o meio social, as relações, a personalidade, o lugar do indivíduo na sociedade, os anseios, as ambições, os temores, os pensamentos, os ideais, ou seja, tudo aquilo que for importante para o indivíduo, do ponto de vista psicológico, naquele determinado momento. 
Pode-se afirmar que qualquer situação psicológica depende do estado da pessoa e, ao mesmo tempo, do ambiente no momento (Lewin, 1973). O indivíduo não se limita apenas à situação presente, uma vez que o passado e o futuro psicológico são partes simultâneas do campo psicológico (Lewin, 1965).

Situação psicológica é definida por Lewin (1973) como a situação vital geral ou a situação momentânea, e, as duas estão relacionadas. A situação vital, sempre influencia a situação momentânea, variando o grau de influência. Ao representar a situação psicológica no espaço vital, deve-se atentar ao fato de que a situação vital geral pode ser utilizada como fundo para uma situação momentânea. O número de regiões representadas no espaço vital psicológico é determinado pelo número de fatos psicológicos separados que existem em um dado momento. As regiões podem ser caracterizadas por meio de três dimensões: fluidez-rigidez proximidade-distância e firmeza-fragilidade (Hall \& Lindzey, 1984).

Quanto ao grau de fluidez-rigidez da região, Lewin (1973) afirmou que, uma região é fluida quando a força necessária para produzir mudanças no meio for pequena. Hall e Lindzey (1984) completam que, no grau de fluidez, a região responde de forma rápida, sendo flexível. Já no grau de rigidez, ocorre uma resistência à locomoção entre regiões, e não há comunicação. O grau de fluidez-rigidez de uma situação desempenha um papel importante e constitui uma das propriedades dinâmicas fundamentais de uma situação psicológica vital (Lewin, 1973).

Em relação ao grau de proximidade-distância, as regiões de uma pessoa podem estar conectadas ou desconectadas. Segundo Lewin (1965), as regiões são conectadas quando os fatos de uma região são acessíveis aos fatos de outra região. Hall e Lindzey (1984) complementam que existe conexidade quando há comunicação entre as regiões. Já as regiões desconectadas possuem como resultado o enfraquecimento da conexão interna e diminuição do grau de dependência mútua. O modo como um grupo se comporta é afetado pela presença ou ausência de conexão (Lewin, 1973).

Uma região conexa pode ser caracterizada como uma região de espaço de livre movimento. É definida como a totalidade de regióes a que a pessoa tem acesso, desde o momento presente, e, no interior da região conexa (Lewin, 1973). Quanto ao grau de firmeza-fragilidade, duas regiões podem estar muito próximas, compartilhar uma fronteira comum, porém, podem não influenciar ou não ser acessível uma a outra, depende da força da resistência oferecida pela fronteira. Dessa forma, a fronteira entre as regiões pode ser firme ou frágil (Hall \& Lindzey, 1984). Dessa forma, Lewin (1965) afirma que a região na qual a pessoa se localiza pode determinar: a qualidade do seu meio imediato; os tipos de regiões adjacentes à atual região; e o significado de uma ação que se locomove em direção ao objetivo, e de uma que se afasta.
Lewin (1965) define locomoção como a mudança de posição de uma pessoa, de uma região para outra. Hall e Lindzey (1984) completam afirmando que é o caminho específico que uma pessoa percorre ao mover-se através de seu espaço vital psicológico. Locomoção entre regiões implica mudança de estrutura do campo (Lewin, 1965), pois ocorre uma reestruturação de todo o espaço vital psicológico (Lewin, 1973).

A maioria dos comportamentos podem ser compreendidos como uma mudança de posição, ou seja, uma locomoção, propõe Lewin (1965). Dessa forma, cada comportamento pode mudar a situação psicológica vital. Existe o comportamento que se adapta a uma situação, e aquele que busca pertencer ao grupo. $\mathrm{O}$ autor destaca que a adaptação a uma região ocorre como uma reação ao meio, na qual o indivíduo reage baseado na forma como ele percebe e compreende o contexto, um processo natural.

No que diz respeito ao comportamento daquele que quer pertencer a um grupo, ou seja, locomover-se para outra região, a questão de pertencer ou não é equivalente a ter uma posição dentro ou fora da região, o que determina os direitos e deveres de cada indivíduo. Sentirse pertencente a determinado grupo, garante o senso de pertença e de segurança de cada pessoa (Lewin, 1965).

Lewin (1965) afirma que o que faz um indivíduo se locomover ou não para uma região é a força. Ela é definida como uma estrutura do espaço de vida, que determina quais locomoções são possíveis em determinado momento, e caracteriza a direção e a intensidade da tendência à mudança. Força resultante é conceituada como a combinação de várias forças que atuam no mesmo ponto, em um determinado momento, entre pelo menos duas regiões do espaço vital.

Existem cinco tipos diferentes de forças. A força impulsora é aquela que se locomove em direção a uma valência positiva e afasta-se de uma negativa. Pode ser impedida por obstáculos físicos e sociais, influenciando o efeito da força impulsora. Essa força recebe o nome de força frenadora. É chamada de força induzida aquela que não corresponde a sua real necessidade, sendo uma vontade do outro. Ao contrário, existe a força correspondente às necessidades do indivíduo. A força que não é necessidade do indivíduo e não é necessidade do outro, recebe o nome de força impessoal (Lewin, 1965).

Em situações de conflito, as forças que atuam sobre o indivíduo são opostas em direção, mas de intensidade igual (Lewin, 1965). No que diz respeito às forças propulsoras, existem três tipos de conflito. O primeiro ocorre quando a pessoa está entre duas valências positivas. Geralmente nesse tipo de conflito a decisão é fácil. O segundo tipo de conflito acontece quando alguma coisa tem, simultaneamente, uma valência positiva e uma negativa, como em situações de medo; nesses casos, a valência positiva costuma perder força, e a valência negativa aumenta, fazendo com que a pessoa se retire do campo. O terceiro tipo acontece quando há duas valências negativas (Lewin, 1975). 
A força é diferente de valência. Valência é a propriedade conceitual de uma região do ambiente psicológico, é o valor daquela região para a pessoa. A valência pode ser positiva ou negativa. A valência é positiva quando a região contém um objeto que reduz a tensão quando a pessoa entra na região. No caso da valência negativa, há um aumento da tensão quando a pessoa entra na região (Hall \& Lindzey, 1984).

Hall e Lindzey (1984) afirmam que uma valência relaciona-se a uma necessidade. $\mathrm{O}$ fato de uma região receber valência positiva ou negativa está ligado diretamente ao estado de tensão do sistema. Lewin (1965) conceitua tensão como "o estado de um sistema em relação ao estado dos sistemas que o rodeiam, a essência e o propósito desta construção é incluir uma tendência para mudar, no sentido de igualar o estado dos sistemas vizinhos" (p. 14). De acordo com Hall \& Lindzey (1984), tensão é um estado da região intrapessoal de uma pessoa referente a outras regiões intrapessoais.

O grau de fluidez-rigidez de uma região, já descrito anteriormente, é determinado pela tensão. Nesse sentido, um campo é muito fluido quando qualquer diferença entre os níveis de tensão dos sistemas desparece rapidamente, uma vez que a tendência de igualar tensões locais não encontra qualquer resistência. Um campo é pouco fluido quando os sistemas correspondentes às necessidades são capazes de manter quantidades diferentes de tensão em um determinado período. Portanto, a pessoa deve ser concebida como tendo grau médio de fluidez na intercomunicação de seus sistemas de tensão, e o grau de fluidez-rigidez varia de acordo com a pessoa e a situação. No entanto, o estado de equilíbrio de um sistema não significa que o sistema seja isento de tensão (Lewin, 1965; 1975).

Em resumo, Lewin (1973) considera que

a condição dinâmica de uma pessoa depende diretamente da sua posição numa certa região. Portanto, em quase todo e qualquer problema psicológico, devemos dar prioridade à questão da região em que uma pessoa está num certo momento ou que mudança de posição está ocorrendo nesse preciso momento (p. 120).

\section{Método}

\subsection{Participantes}

O presente estudo teve como foco quatro homossexuais, com idade variando de 27 a 47 anos, e os aspectos considerados foram: sexo, nível socioeconômico e grau de escolaridade. Quanto ao nível socioeconômico, percebeu-se que todos os entrevistados são independentes economicamente da família de origem e do companheiro. Constitui requisito que a família de origem tivesse conhecimento da condição homossexual do membro do grupo familiar.
O critério de exclusão atingiu indivíduos que não se adequaram a essas características ou que não concordaram em participar do estudo. Com o intuito de preservar a identidade dos participantes, eles receberam nomes fictícios.

O Entrevistado 1, Fernando, é formado em Arquitetura e exerce a profissão. Possui um relacionamento homossexual há 9 anos, e há 7 anos moram juntos. Assumiu sua orientação afetivo-sexual aos 24 anos, na fase adulta.

O entrevistado 2, Marcos, nasceu no interior de Goiás. Tem 47 anos e atualmente é funcionário público. Percebeu-se homossexual aos 18 anos. Possui um relacionamento homoafetivo há 10 anos.

A entrevistada 3, Marina, tem 27 anos, é psicóloga, formada há 6 anos. É natural do interior de Goiás, assumiu a homossexualidade ao mudar-se para a cidade de Goiânia-GO e iniciar o curso de Psicologia. Está em um relacionamento homossexual há 2 anos e meio.

A entrevistada 4, Renata, é empresária, tem 31 anos. Está em um relacionamento homoafetivo há 16 anos, e há poucos meses realizou o contrato de união homoafetiva. Atualmente, ela e sua companheira fazem tratamento médico para engravidar.

\section{Procedimento da Análise Compreensiva dos Dados}

Como plano teórico e de intervenção, para chegar à compreensão do significado de família para homossexuais, foi realizada uma análise compreensiva do discurso, de acordo com os quatros passos propostos no método fenomenológico de Giorgi (1985). É comum referir-se ao método fenomenológico no singular. Entretanto, segundo Moreira (2002), torna-se importante ressaltar que apesar de existir apenas um método fenomenológico, ele admite algumas variantes, dentre elas as propostas por Gomes (1998), Amedeo Giorgi (1985) e Forghieri (2004).

Giorgi (1985), norteado pela fenomenologia e o seu conceito de voltar às coisas mesmas, possui o intuito de realizar descobertas genuínas em relação ao fenômeno pesquisado. Para atingir o objetivo proposto pelo autor, torna-se necessário seguir quatro passos essenciais. $\mathrm{O}$ primeiro passo tem por finalidade captar o sentido do todo, desse modo, a entrevista deve ser transcrita, conforme fala original do entrevistado, para captar o sentido geral do todo. O segundo passo propõe uma releitura da entrevista, com o objetivo de identificar as unidades significativas com base em uma perspectiva psicológica e focada no fenômeno pesquisado (Giorgi, 1985) O terceiro passo descrito pelo autor refere-se à transformação das expressões cotidianas do entrevistado para uma linguagem psicológica, com ênfase ao fenômeno pesquisado. No quarto e último passo, cabe ao pesquisador realizar a síntese das unidades significativas transformadas em uma declaração consistente da estrutura do aprendizado, que constitui a estrutura da experiência vivenciada pelo 
sujeito. Essa síntese das unidades de sentido ao serem estudadas em suas convergências e em suas divergências constituirão as categorias

\section{Resultados e Discussão}

\subsection{Processo de Autodenominação Sexual}

Todos os entrevistados relataram que se percebiam diferentes em algo desde a infância, porém somente na adolescência ou fase adulta tiveram certeza a respeito da diferença. Fernando relata: "Hoje em dia eu percebo que é uma coisa nata, e ela só demora um tempo para aflorar até você perceber o que é aquilo (...) aí não tinha muita compreensão do que é aquilo diferente que você sente, até que chega o momento que você descobre".

O processo de autodenominação é o momento em que o indivíduo assume para si mesmo sua orientação afetivo-sexual. No que diz respeito à autodenominação, Fernando esclarece: "tem que entrar em um processo até conseguir aceitar e perceber que aquilo não faz mal pra ela, que ela não está agredindo ninguém, que não é uma doença. Então acho que precisa desse período de compreensão e entendimento sobre o que é a homossexualidade".

O fato de assumir a homossexualidade ao final da adolescência está diretamente ligado à rede de apoio da qual o indivíduo participa. Nesse período, o sujeito inicia o contato com amigos e grupos homossexuais, passa a frequentar um ambiente social no qual é aceito e que é coerente com seus questionamentos (FérnandezMartos, 1998).

O processo de aceitação da homossexualidade de Marcos ocorreu conforme relato dos autores. Quando questionado a respeito de quem foi a primeira pessoa a ficar sabendo de sua homossexualidade, diz: "faz tanto tempo, mas pelo que recordo, foi um amigo da escola que eu sabia que era, acho que ele me deu segurança pra falar".

Ressalte-se que antes de assumirem a homossexualidade, os quatro entrevistados tiveram relacionamentos heterossexuais durante a adolescência. Afirma Marina: "Tive algumas experiências com homens, de relacionamento afetivo, relacionamento sexual nunca tive com homens".

Deve-se lembrar que, apesar de muitos indivíduos assumirem a homossexualidade na fase da adolescência ou adulta, admitir-se homossexual é um processo continuo tanto para ele, quanto para a família da qual faz parte (Cancissu, 2007). Processo pode ser conceituado como uma progressão que permite movimentos para frente e para trás, influenciada por fatores ambientais, culturais e emocionais (McGoldrick, 2003).

O processo de aceitação no qual a família passa, inclui, para os pais, se perceberem como sendo pais de um filho homossexual, envolve questões de autorreconhecimento, auto-identificação, auto-revelação e integração de uma identidade modificada (McGoldrick, 2003).
Não se trata de um processo individual, uma vez que as pessoas são afetadas pelo mundo e também o afeta. $\mathrm{O}$ comportamento humano deve ser considerado a partir do mundo, ou seja, a compreensão do comportamento baseia-se na relação pessoa-organismo-meio (Ribeiro, 2011).

Essa relação pessoa-organismo-meio remete ao conceito de pôr-se em acordo com o meio ambiente, proposto pela teoria organísmica de Kurt Goldstein. Considerase que o meio exerce influência sobre o organismo, por isso o ideal é que homem e ambiente estejam em acordo, a fim de propiciar meios mais saudáveis para a autorrealização. Torna-se importante salientar que em alguns casos, o ambiente pode exercer forte pressão no indivíduo, gerando uma paralisação, que resulta na incapacitação para progredir (Ribeiro, 1999).

A afirmação dos autores corrobora a experiência de Fernando, que expõe: "Não teve nenhum momento de crise, aquele coisa assim, foi um processo, acho que se resume assim, como um processo. Compreender que existia algo diferente, tentar entender o que era, e aceitar aquilo".

A vivência dos entrevistados no que diz respeito ao processo de autodenominação sexual, remete à teoria paradoxal da mudança. Segundo Besser (1971), "a mudança ocorre quando uma pessoa se torna o que é, não quando tenta converter-se no que não é” (p. 110). Nesse sentido, percebe-se que houve mudanças quando os entrevistados assumiram o que eles realmente eram, homossexuais.

\subsection{Reconfiguração do Campo Após a Descoberta da Homossexualidade}

No momento em que o indivíduo assume sua orientação afetivo-sexual, ocorre uma locomoção no campo. A locomoção é uma mudança de posição da pessoa, de uma região para outra (Lewin, 1965). E ainda, quando ocorre a locomoção, há uma mudança de estrutura do campo, pois é necessária uma reestruturação do espaço vital psicológico (Lewin, 1965; Lewin, 1973).

A reestruturação do campo torna-se necessária, pois, quando ocorrem mudanças críticas e transições, o sistema familiar como um todo é afetado por reflexos e impactos de diferentes formas (McGoldrick, 2012). Quando acontece a revelação da orientação afetivo-sexual para a família, o indivíduo se locomove da região heterossexual para a região homossexual. Pertencer a essa nova região pode determinar os direitos e deveres do indivíduo no grupo ao qual pertence (Lewin, 1965), bem como o espaço que frequenta, o que modifica a configuração do meio psicológico e da valência das regiões desse meio.

Para três entrevistados, Fernando, Marina e Renata, ao assumirem a homossexualidade para a família houve mudanças na estrutura do campo, pois seu espaço vital psicológico foi modificado. Para os entrevistados, ocorreram momentos de não aceitação familiar, como descreve Marina: "Foi muito difícil lidar com a não aceitação, 
foi um momento de conflito, para todos nós, mas também mudaram algumas coisas".

No processo de Marcos, como ele optou por não contar a respeito de sua homossexualidade, não houve conflitos familiares e questionamentos. Ele relata: "olha, eu deixei acontecer. Hoje eles sabem, eu deixei a coisa fluir no dia a dia, as coisas foram acontecendo normalmente, não teve choque, conflito, nada disso, deixei acontecer para que fosse tranquilo, e é tranquilo hoje".

Percebe-se que a locomoção de Marcos da região heterossexual para a região homossexual ocorreu sem grandes reconfigurações na estrutura do campo, pois a forma escolhida por ele permitiu que a locomoção fosse fluida.

Fernando e Renata descreveram como cada membro de seu núcleo familiar reagiu à homossexualidade, e, apesar da não aceitação de alguns membros, os dois entrevistados obtiveram o apoio de pelo menos um membro familiar. Dessa forma, Renata expõe que, apesar da não aceitação de algumas pessoas do seu círculo familiar, "minha irmã me deu muito apoio, foi ela quem me ajudou".

Fernando e Marcos recebem o apoio das duas famílias. Para Marcos, o apoio mútuo familiar exerce influência da seguinte forma: "É muito mais tranquilo né, a liberdade é maior, a confiança, acho que o casamento se torna um porto seguro quando é dessa forma".

A respeito do processo de aceitação familiar, Marina relata que ocorreu uma fase de adaptação da família, o que permitiu que houvesse mudanças significativas. Antes de assumir a homossexualidade, Marina estava no movimento de afastamento e após assumir a sua homossexualidade, houve o movimento de aproximação de seu núcleo familiar. Quando questionada a respeito de mudanças, Marina relata:

Aproximou bastante. Porque antes deles ficarem sabendo, eu tinha um movimento de afastamento, por não saber como me comportar, o que falar, como falar, eu acabei me afastando, principalmente dos meus pais e dos meus irmãos. E ai, quando a homossexualidade se tornou algo claro, é logico que nós passamos por um período difícil, por volta de 2 anos, eu considero um período de adaptação, algo normal mesmo, que tem que ocorrer. Depois desse período de aceitação nós começamos com esse movimento de aproximar, eu com meus pais e meus irmãos.

Em relação à reconfiguração do campo de Renata, ocorreu uma não aceitação, atitude já esperada. Porém, ela e sua companheira decidiram fazer o contrato de união homoafetiva, que teve como consequência a confirmação delas como um casal. O contrato gerou maior aceitação e respeito da família de Renata, assim como maior aceitação da família da companheira, além de mudanças referentes ao acesso e direitos do casal e diminuição do sentimento de aprisionamento.
A experiência de Renata e sua companheira constitui algo novo, pouco explorado na literatura, visto que o contrato de união homoafetivo é recente. Carter e McGoldrick (1995) ressaltam que a falta de rituais normativos durante o ciclo de vida, como o casamento, dificulta o reconhecimento da família. No caso de Renata, a experiência do contrato de união homoafetiva auxiliou o reconhecimento familiar de sua orientação sexual.

\subsection{Constituição Familiar Atual}

Torna-se interessante investigar a constituição familiar atual de cada entrevistado, uma vez que muitos homossexuais não possuem sua família de origem como rede de apoio primária. O que ocorre geralmente e que eles escolhem uma família para ser essa rede de apoio (Cancissu, 2007). A mudança na constituição familiar pode ocorrer em situações de conflito. Um tipo de conflito é aquele em que a situação possui uma valência positiva e uma negativa. Com o passar do tempo, a valência negativa aumenta a força, ao passo que a positiva perde força, resultando na retirada do campo (Lewin, 1975).

No relato de vida de Renata, percebe-se que sua formação familiar atual é composta por ela e sua companheira, constituindo, desse modo, uma família homoafetiva sem filhos. Essa formação deve-se ao fato de ter ocorrido conflito com sua família de origem no momento da descoberta da orientação afetivo-sexual. Dessa forma, o relacionamento homossexual tornou-se uma valência positiva, mas a família de origem recebeu valência negativa. Atualmente, a família de origem ainda participa do campo de Renata, porém, não com a mesma intensidade.

A vivência de Renata corrobora a afirmação de Lewin (1975), ao explicar que, no segundo tipo de conflito, quando há uma valência positiva e uma negativa, a valência positiva costuma perder força e a valência negativa aumenta, fazendo com que a pessoa se retire do campo. Porém, no caso de Marina, a valência negativa não perdeu totalmente sua força, pois a região família de origem ainda permanece no campo.

A família de Marina é constituída pela família de origem, e inclui a família extensa e a companheira. Em sua história de vida, antes da descoberta da homossexualidade pela família, Marina não se aproximava da família de origem, pelo estado de tensão do campo, visto que a tensão é um estado da região intrapessoal de uma pessoa relativo a outras regiões intrapessoais (Hall \& Lindzey, 1984).

O movimento de afastamento de Marina é justificado pela afirmação de que a condição dinâmica de uma pessoa depende diretamente da sua posição em uma certa região (Lewin, 1973). Percebe-se que, sua condição dinâmica estava sendo afetada de tal modo que foi necessário afastar-se. Compreende-se que contar a respeito da homossexualidade teve como consequência a busca do equilíbrio em seu campo, e que o equilíbrio de um sistema não significa que ele esteja isento de tensão (Lewin, 1975). 
Atualmente, o campo de Marina em relação à região família de origem, parece ser muito fluido, pois há uma tendência em igualar as tensões sem encontrar resistências (Lewin, 1965). Marina descreve: "Hoje nós somos bem juntinhos, convivemos de forma tranquila, aceitam minha companheira. (...) O apoio da minha família é muito importante pra mim.”.

Em relação à experiência de vida de Fernando, percebe-se que em seu campo, no que diz respeito às dimensões das regiões, na região família há conexidade. Atualmente, o entrevistado considera família aquela de origem (nuclear e extensa) e a família do companheiro. Fernando relata que a família de origem materna possui uma força centrípeta em seu campo, já a família de origem paterna tem uma força centrífuga, e sua família nuclear também possui o movimento centrípeto. A força centrípeta pode ser utilizada como proximidade, e força centrífuga, distância.

Dessa forma, o grau de proximidade da região família de origem materna e família nuclear são próximas, conexas. As regiões são conectadas quando os fatos de uma região são acessíveis aos fatos de outra região (Lewin, 1975). A dimensão proximidade-distância pode ser percebida na experiência de Fernando, quando descreve:

A família nossa tem dois lados, o lado que é muito unido e o lado que é muito separado. Até engraçado, uma família de quatorze irmãos onde todos são reunidos, chega até ser demais às vezes, e do outro lado a família do meu pai. (...) uma família de três irmãos, em que um não se relacionava com os outros. Então eu tenho esses dois contextos, uma família muito unida e a outra um pouco complicada. E graças a Deus... nossa perspectiva de família puxou para o lado da união, somos extremamente envolvidos, muito unidos, quando acontece qualquer coisa todo mundo está presente, é todo mundo meio palpiteiro, puxou para o lado da minha mãe. Acho que tanto meu pai quanto minha mãe conseguiram perceber isso... o que fiz com que a gente tivesse esses valores que eram importantes pra eles.

Para Fernando, possuir a dimensão proximidade é algo positivo, dessa forma ele pode realizar locomoções de um ponto para outro, sem ser necessário deixar sua região, pois, como afirma Lewin (1973), nas regiões conectadas há espaço de livre movimento. Carter e McGoldrick (1995) ressaltam que quando a proximidade com a família de origem possui um grau elevado, e há dificuldades em constituir sua própria família nuclear, pode ser que o individuo possua conflitos familiares que precisem ser solucionados.

Considerando as afirmações anteriores, pode-se considerar que, em relação ao campo de Marcos, as regiões são fluidas e há proximidade. Tal afirmação pode ser constatada, visto que, atualmente, a família de Marcos é formada por ele e seu companheiro, que formam um casal homoafetivo sem filhos. Porém, apesar de considerar o companheiro um membro da família, Marcos não exclui seu grupo de origem.

Percebe-se que a proximidade na região família de origem de Marcos só não possui uma força maior pelo fato de sua mãe e irmãos não residirem na mesma cidade que o entrevistado. Marcos afirma: "Hoje, minha família é com quem eu convivo no dia a dia, que é meu companheiro". Quando questionado sobre a qualidade do contato com a família de origem, esclarece "Nossa, é muito. Com minha mãe, meus irmãos, contato com todo mundo, normal. Eles fazem parte da minha família".

A experiência de Marcos corrobora a afirmação de que a região na qual a pessoa se localiza pode determinar a qualidade do seu meio imediato (Lewin, 1965). Dessa maneira, Marcos localiza-se em uma região fluida e conectada, o que gera qualidade em seu campo. Para o entrevistado, o campo configura-se dessa forma em virtude da maneira com que ele se comporta: "eu sempre transmiti respeito, com tudo mundo, não só a família, sempre fui muito discreto, cuidadoso com minhas atitudes".

\subsection{Significado de Família para Homossexuais}

Significado de família para homossexuais tornou-se uma categoria de investigação uma vez que a constituição familiar tem sofrido alterações, e o que se denomina família atualmente pode não ter o mesmo significado que décadas atrás (Santos, 2004). Nesse sentido, surge o questionamento: "como os homossexuais conceituam família?”. Os entrevistados Renata e Marcos concordam ao dizer que família é a base de um indivíduo, Renata complementa: "Família é tudo... acho que é a base, é amor, é afeto, é carinho, é educação".

Marina e Fernando conceituam família conforme a perspectiva de quem a constitui. Para Marina, família é formada por meio de laços sanguíneos e afetivos: "um grupo de pessoas, reunidos por laços sanguíneos ou afetivos". Já Fernando configura família como a junção da família nuclear, da família extensa e da rede de apoio social: "a noção e a definição que eu tenho de família seriam as pessoas que te criaram, que te cuidam, estão sempre do seu lado, aquela pessoa que está sempre ali, que você pode contar incondicionalmente, que são os seus irmãos, pais, tios, primos."

Os relatos dos entrevistados definem que a família não pode ser limitada a laços sanguíneos, abrange qualquer ligação baseada na confiança, suporte mútuo e desejo comum de compor uma família. Corrobora com o conceito de rede informal de parentesco proposto por McGoldrick (2012), no qual família vai além da estrutura biológica e abrange qualquer pessoa que seja um apoio importante.

Um dado importante constatado na pesquisa é o de que as mulheres entrevistadas, Renata e Marina, pos- 
suem o desejo de constituir uma família homoparental com filho biológico. Renata expõe: "Pelo sonho de ser mãe, tanto meu quanto dela. Nós temos planos para o futuro, queremos aumentar nossa família, queremos de fato constituir uma família”.

No que diz respeito à história de vida de Marina, percebe-se que, apesar da homossexualidade, os pais têm a expectativa de que a filha tenha filhos. A entrevistada relata também ter o sonho de ser mãe, porém é uma expectativa individual e não do casal: "Eu tenho muita vontade, quero fazer uma inseminação, quero ficar grávida de fato, ver como é desde o início, a barriga crescer e tudo mais, quero ver o processo todo. (...). Ela tá começando a acostumar com essa ideia, mas não sei se é um plano nosso não, é mais meu mesmo".

Na vivência de Marcos, sua família é constituída por ele e seu companheiro, um casal homoafetivo sem filho. Ele relata que já pensaram em adotar um filho. Tal vontade não prevalece no momento. Marcos explica ter sido uma situação específica, pois havia uma criança de quem eles se aproximaram emocionalmente: "Íamos adotar uma criança, uma menina da cidade dele que perdeu a mãe, linda a menina, mas não deu certo, no final a avó dela acabou ficando com ela. Mas foi um fato específico, por causa dela. Hoje eu não tenho vontade". O entrevistado entende que não é o momento ideal para adoção de uma criança, pois ela precisa de dedicação, condição que ele não possui.

A família de Fernando é constituída por sua família de origem e inclui a família do companheiro. Ele explica que o companheiro faz parte da família, no entanto, para ele, eles não configuram uma família, por não terem filhos. Por intermédio do relato dos entrevistados, pode-se afirmar que as mulheres possuem o desejo de constituírem família homoafetiva com filhos biológicos, não se trata de um desejo apenas feminino. Os homens entrevistados alegaram que atualmente não é o momento adequado para a configuração de família homoafetiva com filho adotivo, em virtude do cuidado e dedicação que uma criança exige, sendo que eles não descartam essa ideia para o futuro.

A experiência de vida dos homens entrevistados confirma a afirmação de Lewin (1973) de que qualquer situação psicológica depende do estado da pessoa e, ao mesmo tempo, do ambiente, no momento. Assim, a situação psicológica atual dos homens entrevistados não inclui ter filhos. Um dado importante para a pesquisa é que todos os entrevistados afirmaram possuir um relacionamento homoafetivo estável.

\section{Considerações Finais}

Esta pesquisa teve por objetivo principal apreender a configuração do significado de família para homossexuais. A compreensão pode ser realizada ao investigar qual o vínculo mantido com a família de origem; ao identificar quais pessoas compõem a família atual de um adulto homossexual; e ainda, ao indagar se ocorreram modificações na família de um adulto homossexual após assumir sua condição.

Percebeu-se que o processo de autodenominação sexual teve inicio ao final da infância e início da adolescência e a confirmação para amigos e membros familiares ocorreu no final da adolescência e fase adulta. Verificouse também a confirmação da orientação afetivo-sexual ocorre primeiro para amigos homossexuais, e posteriormente, para a família.

A forma como a família de origem reage após a descoberta da homossexualidade serviu de base para que os colaboradores constituíssem suas famílias. Desse modo, aqueles que receberam apoio da família de origem irão incluí-la em seu campo. Observou-se que os colaborados da pesquisa que não tiveram sua sexualidade aceita pela família de origem, reconfiguraram o campo no que tange aos contatos mantidos com as famílias de origem e incluíram uma nova família como rede de apoio. O que se constata, tanto no caso dos que foram aceitos pelos familiares, quanto nos que não foram aceitos pelos familiares, é que o significado de família permaneceu inalterado.

Foi possível verificar que os casais homossexuais passam por dois momentos de aceitação familiar: o primeiro, quando ocorre a autodenominação; o segundo, quando se inicia um relacionamento homoafetivo.

Percebeu-se que, dentre os problemas enfrentados por casais homossexuais, está a dificuldade de aceitação familiar, por não possuírem rituais normativos, assim como o casamento. Com o avanço das leis que defendem os homossexuais, existe o contrato de união homoafetivo, que confere ao casal homossexual os mesmos direitos do heterossexual. A disposição legal pode contribuir para que os casais homossexuais sofram menos preconceito, tanto familiar, quanto da sociedade.

Somente uma entrevistada firmou o contrato de união homoafetiva com sua companheira. Ela relata que após a assinatura, ela se percebeu confirmada como parte de um casal perante a sociedade. Tal confirmação deve-se ao fato de a família de origem da entrevistada ter aceitado a relação e respeitado a decisão das companheiras. Afirma-se, desse modo, que a reconfiguração da região social interferiu na região pessoal.

Dessa forma, torna-se interessante para futuras pesquisas investigar o reconhecimento familiar dos casais que estabeleceram o contrato de união homoafetiva, em relação aos casais que não efetivaram. Em relação aos temas pesquisados, família e homossexualidade, existe muita literatura em psicologia a respeito dos temas, entretanto são poucas as que fazem junção de família e homossexualidade. Percebeu-se que apesar de todas as mudanças que ocorreram nas últimas décadas no que diz respeito aos temas família e sexualidade, a família continua mantendo o papel fundamental de organizadora da sociedade. 


\section{Referências}

Anjos, G. (2002). Homossexualidade, direitos humanos e cidadania. Sociologias, 7, 222-225.

Besser, A. R. (1971). A teoria paradoxal da mudança. Em J. Fagan \& I. L. Shepherd, Gestalt-terapia: teoria, técnicas e aplicações (pp.110-115). Rio de Janeiro: Zahar.

Borges, R. C. (2009). Pais e mães heterossexuais: relatos acerca da homossexualidade de filhos e filhas (Dissertação de Mestrado não publicada). Faculdade de Filosófica, Ciências e Letras de Ribeirão Preto da Universidade de São Paulo (USP), Ribeirão Preto.

Brasil. Superior Tribunal Federal. (2011). Art. 226. A família, base da sociedade, tem especial proteção do Estado. Acesso em 11 de outubro de 2011. Disponível no World Wide Web: http://www.stf.jus.br/portal/constituicao/artigo.asp\#ctx1

Cancissu, C. R. P. (2007). Lésbicas, família de origem e família escolhida: um estudo de caso (Dissertação de Mestrado não publicada). Pontifícia Universidade Católica de São Paulo (PUC-SP), São Paulo.

Carter, B., \& McGoldrick, M. (1995). As mudanças no ciclo de vida familiar: uma estrutura para a terapia familiar. Porto Alegre: Artmed.

Férnandez-Martos, J. (1998). Homossexualidade: ciência e consciência. Em V. Marciano, G. Javier, M. F. M. José, L. Pablo, R. Gregorio, \& H. Gonzálo (Orgs.), Esclarecimentos fundamentais: nome, definição, tipos e normalidade (pp. 7-15). São Paulo: Edições Loyola.

Forghieri, Y. C. (2004). Psicologia fenomenológica: fundamentos, métodos e pesquisa. São Paulo: Pioneira Thomson Lerning.

Giorgi, A. (1985). Shetch of psychological phenomenological method. Em C. Aanstoos, W. F. Fisher, A. Giorgi \& F. J. Wertz (Orgs.), Phenomenology and psychological research (pp. 8-22). Pittsburgh: Duquesne University Press.

Gomes, W. (1998). Fenomenologia e pesquisa em Psicologia. Porto Alegre: Editora da Universidade/UFRGS.

Hall, C. S., \& Lindzey, G. (1984). A teoria de campo: Lewin. Em C. Hall \& G. Lindzey (Orgs.), Teoria da personalidade, Vol. 3 (pp. 33- 85). São Paulo: EPU.

Lewin, K. (1965). Teoria de campo em ciência social. São Paulo: Pioneira.

Lewin, K. (1973). Princípios de psicologia topológica. São Paulo: Cultrix.

Lewin, K. (1975). Teoria dinâmica da personalidade. São Paulo: Cultrix.

McGoldrick, M. (2003). Novas abordagens da terapia familiar: Raça, cultura e gênero na prática clínica. São Paulo: Roca.

McGoldrick, M. (2012). Genograma: Avaliação e intervenção familiar. Porto Alegre: Artmed.
Mello, L. (2005). Outras famílias: a construção social da conjugalidade homossexual no Brasil. Cadernos Pagu, 24, 197-225.

Menezes, A. B (2005). Análise da investigação dos determinantes do comportamento humano (Dissertação de Mestrado não publicada). Universidade Federal do Pará (UFPa), Belém.

Moreira, D. A. (2002). O Método Fenomenológico na Pesquisa. São Paulo: Thomson Pioneira.

Palma, Y. A., \& Levandowski, D. C. (2008). Vivências pessoais e familiares de homossexuais femininas. Psicologia em Estudo, 13, 771-779.

Ribeiro, J. P. (1999). Gestalt-terapia de curta duração. São Paulo: Summus.

Ribeiro, J. P. (2011). Conceito de mundo e de pessoa em Gestaltterapia: Revisitando o caminho. São Paulo: Summus Editorial.

Santos, C. (2004). A parentalidade em famílias homossexuais com filhos: um estudo fenomenológico da vivência de gays e lésbicas (Tese de Doutorado não publicada). Faculdade de Filosofia, Ciências e Letras de Ribeirão Preto da Universidade de São Paulo (USP), Ribeirão Preto.

Taquette, S. R., Vilhena, M. M., Santos, U. P. P., \& Barros, M. M. V. (2005). Relatos de experiência homossexual em adolescentes masculinos. Ciência \& Saúde Coletiva, 10, 399-417.

Uziel, A. P. (2002). Família e homossexualidade: velhas questões, novos problemas (Tese de Doutorado não publicada). Universidade Estadual de Campinas (Unicamp), Campinas.

Zinker, J. C. (2001). A busca da elegância em psicoterapia: uma abordagem gestáltica com casais, famílias e sistemas íntimos. São Paulo: Summus.

Mariana Alvarenga - Graduada em Psicologia pela Pontifícia Universidade Católica de Goiás (PUC-Goiás), Especialista em Gestalt-terapia (ITGT/PUC-Goiás), Psicóloga associada ao Instituto de Treinamento e Pesquisa em Gestalt-terapia de Goiânia - ITGT. E-mail: marianalvarenga@hotmail.com

Marta Carmo - Psicóloga, Especialista em Gestalt-terapia pelo Instituto de Treinamento e Pesquisa em Gestalt-terapia de Goiânia (ITGT), Mestre em Psicologia do Desenvolvimento pela Universidade Católica de Goiás (UCG). Foi professora da Universidade Paulista (UNIP). Atualmente é professora da Pontifícia Universidade Católica de Goiás (PUC-GO), professora Substituta da Universidade Federal de Goiás, professora do Instituto de Treinamento e Pesquisa em Gestalt-terapia de Goiânia (ITGT) e psicoterapeuta na Alter Consultórios de Psicologia. E-mail: martacarmo@terra.com.br

Recebido em 28.05.12 Primeira Decisão Editorial em 26.05.13 Segunda Decisão Editorial em 09.06.13 Aceito em 26.06.13 